\title{
Um estudo inicial sobre modelagem de florestas
}

\author{
Pedro H. G. Bouzon Dayhanne I. L. Wolff Lívia A. Schulze \\ Instituto de Ciência e Tecnologia, ICET, UFVJM \\ 39803-371, Teófilo Otoni, MG \\ E-mail: peubouzon@gmail.com, dayhanne_lwolff@hotmail.com.br, liviaschulze@hotmail.com
}

Jaqueline M. Silva

Universidade Federal dos Vales do Jequitinhonha e Mucuri - ICET

39803-371, Campus Mucuri, Teófilo Otoni, MG

E-mail: jaqueline.silva@ufvjm.edu.br

\section{Resumo}

\section{Introdução}

Em função da variedade de parâmetros que influenciam o crescimento da vegetação, tais como índice pluviométrico e quantidade de nutrientes disponíveis no solo, modelar a dinâmica de crescimento de árvores em florestas não é um trabalho trivial.

Com os avanços científicos, observou-se que não há progresso sem sustentabilidade, visando um uso consciente dos recursos naturais. Este trabalho tem por objetivo apresentar um modelo para corte sustentável, onde a floresta mantém a sua configuração inicial de extração de madeira e o valor econômico das árvores seja o maior possível, sem dizimar completamente a floresta.

\section{O modelo}

Como pressuposição inicial, as árvores que morrem durante o ano são desconsideradas no modelo. Supõe-se que cada muda plantada sobreviverá até ser cortada.

Árvores de diferentes tamanhos têm valores econômicos diferentes e portanto, distribui-se as árvores na floresta em classes, que possuem intervalos de altura e valor econômico definidos hipoteticamente conforme apresenta a Tabela 1.

\begin{tabular}{|c|c|c|c|c|c|c|c|c|c|}
\hline Classe & 1 (muda) & 2 & 3 & 4 & 5 & 6 & 7 & 8 & 9 \\
\hline Valor econômico $(\mathrm{R} \$)$ & Nenhum & 50 & 100 & 150 & 200 & 250 & 300 & 350 & 400 \\
\hline Intervalo de altura $(\mathrm{m})$ & {$[0,1)$} & {$[1,2)$} & {$[2,3)$} & {$[3,4)$} & {$[4,5)$} & {$[5,6)$} & {$[6,7)$} & {$[7,8)$} & {$[8,9]$} \\
\hline
\end{tabular}

Tabela 1: Classificação de altura e valores econômicos das árvores

No modelo, a equação matricial que descreve o corte sustentável é $G x-y+R y=x$. Sendo $G x$ a configuração no final do período de crescimento arbóreo, $y$ o corte, $R y$ a reposição de mudas e $x$ a configuração inicial da floresta. O vetor $x$ é responsável por armazenar o número de árvores da $i$-ésima classe que sobrevive ao corte. Ele também informa a configuração inicial da floresta. A matriz $G$ é da forma: 


$$
G=\left[\begin{array}{cccccc}
1-g_{1} & 0 & 0 & & \ldots & 0 \\
g_{1} & 1-g_{2} & 0 & & \ldots & 0 \\
0 & g_{2} & 1-g_{3} & & \ldots & 0 \\
\vdots & \vdots & \vdots & & \vdots & \vdots \\
0 & 0 & 0 & \ldots & 1-g_{n-1} & 0 \\
0 & 0 & 0 & \ldots & g_{n-1} & 1
\end{array}\right]
$$

Sabendo que $g_{i}$ é a fração das árvores da $i$-ésima classe para a $(i+1)$-ésima classe durante um período de crescimento e $\left(1-g_{i}\right)$ a fração das árvores que permanecem na $i$-ésima classe durante um período de crescimento. Assim, o produto $G x$ informa a configuração da floresta após o crescimento:

$$
G x=\left[\begin{array}{c}
\left(1-g_{1}\right) x_{1} \\
g_{1} x_{1}+\left(1-g_{2}\right) x_{2} \\
g_{2} x_{2}+\left(1-g_{3}\right) x_{3} \\
\vdots \\
g_{n-2} x_{n-2}+\left(1-g_{n-1}\right) x_{n-1} \\
g_{n-1} x_{n-1}+x_{n}
\end{array}\right]
$$

O vetor $y$ informa a quantidade de árvores cortadas de cada classe e a quantidade total de árvores cortadas que é equivalente à quantidade de mudas a serem plantadas. Assim, considerando a matriz de reposição $R$ definida abaixo,temos a configuração de árvores plantadas após cada corte:

$$
R=\left[\begin{array}{cccc}
1 & 1 & \ldots & 1 \\
0 & 0 & \ldots & 0 \\
\vdots & \vdots & & \vdots \\
0 & 0 & \ldots & 0
\end{array}\right]
$$

$$
R y=\left[\begin{array}{c}
y_{1}+y_{2}+\ldots+y_{n} \\
0 \\
\vdots \\
0
\end{array}\right]
$$

A matriz de reposição $R$ é assim definida para que o produto de $R$ por $y$, represente a configuração de árvores plantadas após cada corte. Supondo que a floresta seja dividida em nove classes, com parâmentros de crescimento hipotéticos $g_{i}=\left(\frac{1}{2}, \frac{1}{3}, \frac{1}{4}, \frac{1}{5}, \frac{1}{6}, \frac{1}{7}, \frac{1}{8}, \frac{1}{9}, 0\right)$ obtêmse uma nova cofiguração da matriz de crescimento $G$ (Ver equação 5). Supondo que 100 mudas foram plantadas, temos a seguinte matriz de configuração inicial (Ver equação 6).

$$
G=\left[\begin{array}{ccccccccc}
0.5 & 0 & 0 & 0 & 0 & 0 & 0 & 0 & 0 \\
0.5 & 0.67 & 0 & 0 & 0 & 0 & 0 & 0 & 0 \\
0 & 0.33 & 0.75 & 0 & 0 & 0 & 0 & 0 & 0 \\
0 & 0 & 0.25 & 0.8 & 0 & 0 & 0 & 0 & 0 \\
0 & 0 & 0 & 0.2 & 0.83 & 0 & 0 & 0 & 0 \\
0 & 0 & 0 & 0 & 0.17 & 0.86 & 0 & 0 & 0 \\
0 & 0 & 0 & 0 & 0 & 0.14 & 0.88 & 0 & 0 \\
0 & 0 & 0 & 0 & 0 & 0 & 0.12 & 0.89 & 0 \\
0 & 0 & 0 & 0 & 0 & 0 & 0 & 0.11 & 1
\end{array}\right] \quad(5) \quad x=\left[\begin{array}{c}
100 \\
150 \\
200 \\
250 \\
300 \\
350 \\
400 \\
450 \\
0
\end{array}\right]
$$

Assim, a matriz que corresponde à configuração após o período de crescimento, será dada pelo produto entre as equações (5) por (6). 


$$
G x=\left[\begin{array}{c}
50 \\
150 \\
200 \\
250 \\
300 \\
350 \\
400 \\
450 \\
50
\end{array}\right]
$$

Como o número de árvores na floresta é fixo até o corte (nenhuma árvore morre) então observa-se um controle da quantidade de árvores armazenadas na variável $s$. Tal que $x_{1}+x_{2}+$ $\ldots+x_{n}=s$.

Sendo $p_{k}$ o valor econômico da classe cortada $k$, o rendimento sustentável ótimo $R T$ será o maior valor tal que:

$$
R T=\frac{p_{k} s}{\frac{1}{g_{1}}+\frac{1}{g_{2}}+\ldots+\frac{1}{g_{k-1}}}
$$

para $k=2,3, \ldots, n$. Ao observarmos a Tabela 2 com os rendimentos, percebe-se que a classe 2 é a mais rentável. Então, se todas as árvores dessa classe são cortadas, a altura máxima da floresta será a altura da classe 2. Assim, o lucro que poderia ser obtido com as outras classes arbóreas será perdido.

\begin{tabular}{|c|c|c|c|c|c|c|c|c|c|}
\hline Classe & 1 (muda) & 2 & 3 & 4 & 5 & 6 & 7 & 8 & 9 \\
\hline Rendimento & Nenhum & 55000 & 44000 & 36667 & 31428.6 & 27500 & 27444.5 & 22000 & 20000 \\
\hline
\end{tabular}

Tabela 2: Rendimento de cada classe de árvore para os parâmentros $g_{i}$

Este fenômeno acontece para todas as classes exceto a última. Observa-se que $R T_{2}>R T_{9}$ mas $R T_{2}<R T_{3}+R T_{4}+\ldots+R T_{9}$. Portanto, a última classe será cortada.

\section{Conclusão}

O modelo não prevê as consequências do corte das árvores na dinâmica de crescimento da vegetação. Tampouco considera as taxas de reprodução e de mortalidade por fatores naturais das árvores. Os resultados obtidos sugerem que a classe que possui maior valor econômico dentro da floresta nem sempre é a mais vantajosa a ser cortada.

Uma vez que o corte de árvores jovens impossibilita a reprodução, o número de mudas será menor, comparando com o número que seria caso uma classe mais adulta fosse cortada.

Os próximos passos deste trabalho incluem um análise das variações das taxas de natalidade e mortalidade na dinâmica da vegetação.

Palavras-chave: Floresta, Sustentabilidade, Rendimento sustentável

\section{Referências}

[1] H. Anton, "Álgebra Linear com Aplicações", 8 $8^{\mathrm{a}}$ Edição, Bookman, Porto Alegre, 2001.

[2] J. M. da Silva, "Sustainability in Flooded Ecossistems, an Integrated View", Tese de doutorado, International Symposium on Mathematical and Computational Biology, 2006. 